\title{
Semaglutide improves postprandial glucose and lipid metabolism, and delays first-hour gastric emptying in subjects with obesity
}

\author{
Julie B. Hjerpsted $\mathrm{PhD}^{1}$ (1) | Anne Flint $\mathrm{PhD}^{1} \mid$ Ashley Brooks $\mathrm{MBChB}^{2}$ | \\ Mads B. Axelsen $\mathrm{MD}^{1}$ | Trine Kvist $\mathrm{PhD}^{1}$ | John Blundell PhD ${ }^{3}$ ()
}

${ }^{1}$ Novo Nordisk A/S, Søborg, Denmark

${ }^{2}$ Covance Clinical Research Unit Ltd, Leeds, UK

${ }^{3}$ Institute of Psychological Sciences, Faculty of Medicine and Health, University of Leeds,

Leeds, UK

\section{Correspondence}

Julie B. Hjerpsted, Novo Nordisk A/S,

Vandtårnsvej 108-110, 2860 Søborg,

Denmark.

Email: jlhj@novonordisk.com

Funding information

This study was funded by an unrestricted grant from Novo Nordisk A/S.

\begin{abstract}
Aim: To investigate the effects of semaglutide on fasting and postprandial glucose and lipid responses, and on gastric emptying.

Materials and methods: This was a randomized, double-blind, placebo-controlled, 2-period, crossover trial. Subjects with obesity $(N=30)$ received once-weekly subcutaneous semaglutide, dose-escalated to $1.0 \mathrm{mg}$, or placebo. After each 12-week treatment period, glucose and lipid metabolism were assessed before and after standardized meals. Gastric emptying (paracetamol absorption test) and peptide YY (PYY) response were also assessed.

Results: Semaglutide treatment significantly lowered fasting concentrations of glucose and glucagon, and increased insulin vs placebo (estimated treatment ratio: 0.95 [95\% confidence interval: $0.91,0.98]$; 0.86 [0.75, 0.98]; 1.45 [1.20, 1.75], respectively). Postprandial glucose metabolism significantly improved with semaglutide vs placebo (incremental area under the curve 0 to 5 hours [iAUC ${ }_{0-5 h}$; estimated treatment difference: glucose $-1.34 \mathrm{mmol} \mathrm{h} / \mathrm{L}[-2.42$, -0.27]; insulin -921 pmol h/L [-1461, -381]; C-peptide $-1.42 \mathrm{nmol}$ h/L [-2.33, -0.51]). Fasting and postprandial lipid metabolism improved with semaglutide vs placebo. First-hour gastric emptying after the meal was delayed with semaglutide vs placebo $\left(\mathrm{AUC}_{\mathrm{0}-1 \mathrm{~h}}\right.$; estimated treatment ratio: 0.73 [0.61, 0.87]); this may have contributed to the lower postprandial glucose increase in semaglutide-treated subjects. Overall gastric emptying ( $\mathrm{AUC}_{0-5 \mathrm{~h}}$ ) was not statistically different between treatments. Fasting and postprandial PYY responses were significantly lower with semaglutide vs placebo $(P=.0397$ and $P=.0097$, respectively).

Conclusion: Semaglutide improved fasting and postprandial glucose and lipid metabolism. Overall gastric emptying was similar to that with placebo; however, the observed first-hour delay with semaglutide may contribute to a slower entry of glucose into the circulation.
\end{abstract}

\section{KEYWORDS}

GLP-1 analogue, glucose metabolism, incretin therapy, insulin analogues, obesity therapy, phase I-II study

\section{1 | INTRODUCTION}

Type 2 diabetes (T2D) is a progressive metabolic disease with increasing prevalence. ${ }^{1}$ T2D is characterized by chronic hyperglycaemia caused by insulin resistance or reduced insulin secretion. ${ }^{1,2}$
Despite the availability of several anti-diabetic drugs, there remains an unmet need for better therapies because a significant proportion of individuals with T2D do not achieve recommended treatment targets for glycaemic control. ${ }^{3}$ Inadequately controlled T2D can result in various complications, including an increased risk of cardiovascular 
disease. ${ }^{1}$ Hyperlipidaemia often co-exists with T2D and is a clear risk factor for atherosclerotic cardiovascular disease. ${ }^{4}$ Controlling hyperlipidaemia is one of the central recommendations of the American Heart Association to reduce the risk of cardiovascular disease. ${ }^{5}$

Glucagon-like peptide-1 (GLP-1) and peptide PYY (PYY) are gut hormones, colocalized in intestinal $L$ cells, that are released in response to nutrient intake. ${ }^{6,7}$ GLP-1 stimulates insulin secretion and inhibits glucagon secretion in a glucose-dependent manner. ${ }^{8}$ At physiological levels, GLP-1 is also associated with an inhibitory effect on gastric emptying and with lowering of body weight, as the result of reduced appetite and decreased energy intake. ${ }^{8-11}$ These properties have led to the development of GLP1 receptor agonists (GLP-1RAs) as a treatment option for individuals with T2D, with one GLP-1RA also developed for the treatment of obesity. ${ }^{12}$

GLP-1RAs have been associated with improved beta-cell function, ${ }^{13,14}$ and have been shown to lower postprandial glucose levels and reduce lipid responses. ${ }^{15-18}$ In addition, GLP-1RAs have the potential to affect gastric emptying, ${ }^{19}$ with an apparently diminished response over time with long-acting GLP-1RAs. ${ }^{20}$

Semaglutide is a human GLP-1 analogue currently in development for once-weekly treatment of T2D. Semaglutide has $94 \%$ structural homology with native human GLP-1 ${ }^{21,22}$ with 3 important modifications: an amino acid substitution at position 8 that makes it less susceptible to degradation by dipeptidyl peptidase-4; lysine acylation of the peptide backbone, with a spacer and C-18 fatty di-acid chain at position 26 that provides strong, specific binding to albumin; and another amino acid substitution at position 34 , which prevents C-18 fatty di-acid binding at the wrong site. ${ }^{21}$ These modifications give semaglutide an extended half-life of approximately 1 week, ${ }^{21}$ making it suitable for once-weekly administration, ${ }^{23,24}$ which has the potential for improving patient compliance and quality of life, ${ }^{22}$ compared with first-generation GLP-1RAs that require once- or twice-daily dosing. ${ }^{25}$ Semaglutide is associated with dose-dependent reductions in glycated haemoglobin (HbA1c) levels and body weight in individuals with diabetes. ${ }^{26}$

Previously, we reported that semaglutide, compared with placebo, reduced body weight and ad libitum energy intake after 12 weeks of treatment. ${ }^{27}$ This finding was supported by different aspects of homeostatic and hedonic appetite parameters. ${ }^{27}$ Here, we report data from the same study on the effects of semaglutide, compared with placebo, on fasting and postprandial glucose and lipid responses, as well as its effects on gastric emptying.

\section{2 | MATERIALS AND METHODS}

\section{1 | Study design}

Details of the study design have been described elsewhere. ${ }^{27}$ Briefly, this was a single-centre, randomized, double-blind, 2-period, placebocontrolled, crossover study (NCT02079870, EudraCT no. 2013000012-24). It was conducted in compliance with the International Conference on Harmonisation Good Clinical Practice guidelines ${ }^{28}$ and the Declaration of Helsinki. ${ }^{29}$

Subjects were randomized $1: 1$ to 1 of 2 treatment sequences, semaglutide-placebo or placebo-semaglutide, and received either semaglutide or volume-matched placebo, administered subcutaneously once-weekly. The starting dose was $0.25 \mathrm{mg}$ ( 4 weeks), escalating to $0.5 \mathrm{mg}$ ( 4 weeks) and thereafter to $1.0 \mathrm{mg}$ ( 4 weeks). Subjects received a 5 th dose of $1.0 \mathrm{mg}$ at the last visit (an in-house stay) of each treatment period, when assessments were conducted. The 2 treatment periods were separated by a washout period of 5 to 7 weeks, to allow for elimination of semaglutide before starting the second treatment period.

\section{2 | Trial population}

Eligible subjects were 18 years of age or older, with obesity, defined as a body mass index (BMI) of 30 to $45 \mathrm{~kg} / \mathrm{m}^{2}, \mathrm{HbA1c}<6.5 \%$ and a stable body weight ( $<3 \mathrm{~kg}$ change during the 3 months prior to screening). Key exclusion criteria included: diagnosis of type 1 or type 2 diabetes; anticipated change in lifestyle (eg, eating, exercise or sleeping pattern, including excessive participation in strenuous exercise, as judged by the investigator) during the trial period; history of chronic or idiopathic acute pancreatitis; personal/family history of medullary thyroid carcinoma or multiple endocrine neoplasia syndrome type 2; previous surgical treatment for obesity; or use of any medication that could interfere with the trial results. Written informed consent was obtained from all participants before any study-related activities commenced.

\section{3 | Assessments and endpoints}

At the end of each 12-week treatment period, on Day 1 of the inhouse stay, subjects were standardized with regard to meals, physical activity and sleep. The last dose of trial drug was administered in the evening. On Day 2, a standardized carbohydrate-rich breakfast was served at 8:00 AM and assessments were performed over a 5-hour postprandial period. The total energy content of the standardized breakfast was $600 \mathrm{kcal}$ (2.51 MJ, approximate macronutrient composition: energy percentage [E\%] 55\% carbohydrate, $30 \mathrm{E} \%$ fat and $15 \mathrm{E} \%$ protein). The breakfast included yoghurt that contained $1500 \mathrm{mg}$ paracetamol (Zentiva, Surrey, UK) to allow measurement of gastric emptying. ${ }^{30}$ Before (fasting) and up to 5 hours after (postprandial) the start of the breakfast, blood was sampled for measurement of glucose, insu-

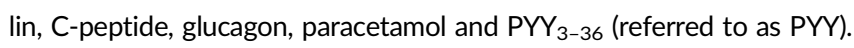
Gastric emptying was assessed by calculating the endpoints derived from paracetamol concentration profiles. Additionally, endpoints were derived from first-hour glucose, insulin, C-peptide, glucagon, paracetamol and PYY concentration profiles.

On Day 4, a standardized fat-rich breakfast was served at 8:00 AM and an 8-hour standardized fat-rich meal test was performed. The standardized fat-rich breakfast had a total energy content of $1000 \mathrm{kcal}$ (4.18 MJ, approximate macronutrient composition: $66 \mathrm{E} \%$ fat, $19 \mathrm{E} \%$ carbohydrate and $15 \mathrm{E} \%$ protein). Before (fasting) and up to 8 hours after (postprandial) the start of the breakfast, blood was sampled for measurement of parameters of lipid and glucose metabolism. Low-density lipoprotein (LDL), high-density lipoprotein (HDL) and total cholesterol were assessed in the fasted state only, while glucose, insulin, C-peptide, glucagon, triglyceride (TG), free fatty acid (FFA), very-low-density-lipoprotein (VLDL) cholesterol and apolipoprotein B48 (ApoB-48) were assessed both in the fasted state and postprandially. 


\subsection{Analytical and statistical methods}

Blood samples were taken from subjects by venepuncture or cannulation, and serum and plasma were prepared using standard procedures. Plasma concentrations of glucagon and PYY were measured using validated competitive radioimmunoassays (RIAs; GL-32K glucagon RIA and PYY-67HK human PYY 3 -36-specific RIA) (both Millipore, UK). Paracetamol was measured in plasma by liquid chromatographytandem mass spectrometry (LC-MS/MS). The following parameters were measured in serum using standard validated methods: ApoB-48 (ApoB-48 Human ELISA; Biovendor Research and Diagnostic Products, UK), glucose, insulin and C-peptide (ADVIA Centaur CP Immunoassay System; Siemens Healthineers, UK), FFA (IL ILab 650 Chemistry Analyser; Diamond Diagnostics, UK), HDL, LDL, total cholesterol, TG and VLDL by ELISA (automated methods: Pacific Biomarkers Inc., USA; for further details see: https://pacbio.com).

Fasting values and paracetamol endpoints were analyzed using a linear mixed model on log-transformed data, including treatment and treatment period as fixed effects and subject as random effect. Incremental area under the concentration-time curves (iAUC) of glycaemic and lipid parameters were analyzed using a linear mixed model, including treatment and treatment period as fixed effects, fasting value as covariate and subject as random effect.

Four subjects did not complete the standardized carbohydraterich breakfast during the second treatment period $(17 \%-40 \%$ of meals not eaten) and were excluded from the statistical analyses of endpoints related to this meal test, with the exception of the data points relating to gastric emptying, as all subjects consumed the paracetamol-containing yoghurt. Two subjects did not complete the standardized fat-rich breakfast and were excluded from the statistical analyses of endpoints relating to this meal test. A sensitivity analysis of gastric emptying was done for the 4 subjects who did not complete the standardized breakfast but who consumed the paracetamolcontaining yoghurt, as well as for 1 subject who, on one occasion, received placebo rather than semaglutide, and 1 subject who had a measurable plasma paracetamol concentration at baseline. Furthermore, sensitivity analyses were performed for glucose and TG endpoints for the 1 subject who received placebo rather than semaglutide on 1 occasion. Findings from the sensitivity analyses supported the overall results.

The effects of gastric emptying on first-hour postprandial glucose absorption were assessed in an exploratory analysis of glucose results, from the same meal as when the paracetamol sampling was performed. Glucose measured before and up to 1 hour after the standardized breakfast ( $\mathrm{AUC}_{0-1 \mathrm{~h}}$ for glucose) was further analyzed, with or without adjustment for the subject-mean-centred log-transformed $\mathrm{AUC}_{0-1 \mathrm{~h}}$ for paracetamol concentration as covariate.

\section{3 | RESULTS}

\section{1 | Subject characteristics}

A total of 30 subjects were randomized to once-weekly semaglutide or placebo. At baseline, mean (standard deviation) age, body weight, height and BMI were 42 (11) years, $101.3(10.5) \mathrm{kg}, 1.73(0.08) \mathrm{m}$ and $33.8(2.5) \mathrm{kg} / \mathrm{m}^{2}$, respectively. Two-thirds of the study subjects were male and $90 \%$ were Caucasian. Two subjects withdrew because of gastrointestinal adverse events during the first treatment period while receiving semaglutide, resulting in 28 subjects who completed both treatment periods.

\section{2 | Glucose metabolism}

\subsection{1 | Glucose}

At the end of the 12-week treatment period, subjects receiving semaglutide had lower mean fasting concentrations of glucose, compared with those receiving placebo (estimated treatment ratio [ETR]: 0.95 [95\% confidence interval $(\mathrm{Cl}): 0.91,0.98] ; P=.0079)$, prior to the standardized carbohydrate-rich breakfast (Table 1). Following the standardized carbohydrate-rich breakfast, postprandial increments (iAUC $\mathrm{C}_{0}$ $5 \mathrm{~h}$ ) for glucose were $38.5 \%$ lower with semaglutide compared with placebo (estimated treatment difference [ETD]: $-1.34 \mathrm{mmol} \mathrm{h} / \mathrm{L}[95 \% \mathrm{Cl}$ : $-2.42,-0.27$ ]; $P=.0163$ ) (Figure 1, Table 1). Before the fat-rich breakfast, fasting concentrations of glucose were significantly lower for subjects treated with semaglutide vs placebo (ETR: 0.95 [95\% Cl: 0.92, 0.98]; $P$.0036) (Table 1). Following the standardized fat-rich breakfast, postprandial values ( $\mathrm{iAUC}_{0-8 \mathrm{~h}}$ ) of glucose were $32.0 \%$ lower with semaglutide compared with placebo (ETD: $-1.41 \mathrm{mmol} \mathrm{h} / \mathrm{L}$; $P=.0087$ ) (Figure S1, Table 1).

\subsection{2 | Insulin and C-peptide}

At the end of the 12-week treatment period, subjects receiving semaglutide had significantly higher mean fasting concentrations of insulin and C-peptide compared with those receiving placebo (ETR: 1.45 [95\% Cl: 1.20, 1.75]; $P=.0005$; and ETR: 1.35 [95\% Cl: 1.20, 1.52]; $P<.0001$, respectively), prior to the standardized carbohydraterich breakfast (Table 1). After the standardized carbohydrate-rich breakfast, postprandial increments (iAUC $\mathrm{C}_{0-5 \mathrm{~h}}$ ) were $43.4 \%$ and $28.7 \%$ lower for insulin and C-peptide, respectively, with semaglutide compared with placebo (ETD: $-921 \mathrm{pmol} \mathrm{h} / \mathrm{L}$ [95\% Cl: $-1461,-381]$; $P=.0018$; and ETD: $-1.42 \mathrm{nmol} / \mathrm{L} \quad\left[\begin{array}{llll}95 \% & \mathrm{Cl} & -2.33, & -0.51\end{array}\right]$; $P=.0033$, respectively) (Figure S1, Table 1).

Before the fat-rich breakfast, subjects treated with semaglutide also had higher fasting concentrations of insulin and C-peptide, although this was only borderline significant for insulin (ETR: 1.18 [95\% Cl: 0.99, 1.41]; $P=.0569$; and ETR: 1.23 [95\% Cl: 1.09, 1.38]; $P=.0012$, respectively, Table 1 ). After the standardized fat-rich breakfast, postprandial values ( $\mathrm{iAUC}_{0-8 \mathrm{~h}}$ ) of insulin and $\mathrm{C}$-peptide were $35.7 \%$ and $30.6 \%$ lower for insulin and C-peptide, respectively, with semaglutide compared with placebo (ETD: $-1105 \mathrm{pmol} \mathrm{h} / \mathrm{L}$, $P=.0028 ;$ and ETD: $-2.25 \mathrm{nmol} h / \mathrm{L}, \quad P=.0005$, respectively) (Figure S1, Table 1).

\subsection{3 | Glucagon}

At the end of the 12-week treatment period, subjects receiving semaglutide had lower mean fasting concentrations of glucagon compared with placebo (ETR: 0.86 [95\% Cl: 0.75, 0.98]; $P=.0224$ ) prior to the standardized carbohydrate-rich breakfast (Table 1). Following the standardized carbohydrate-rich breakfast, there was no significant 


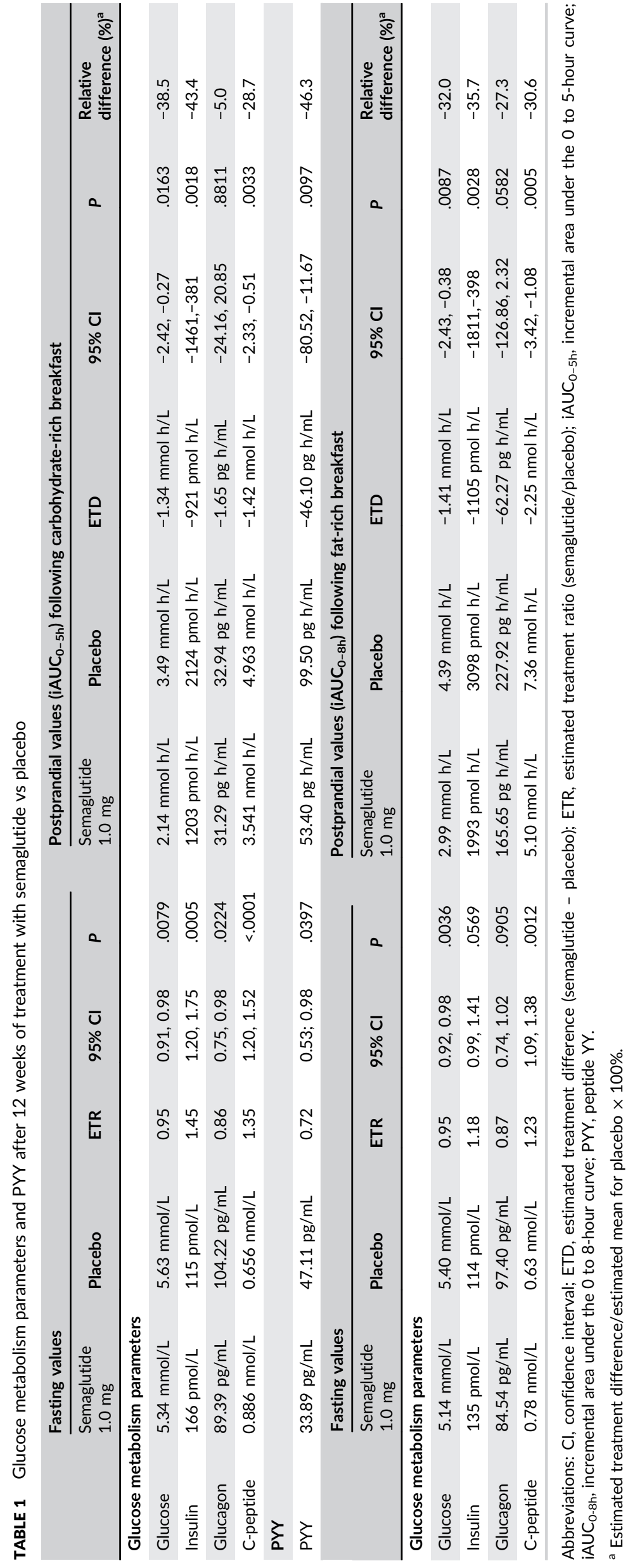

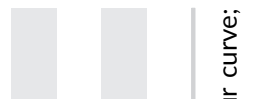



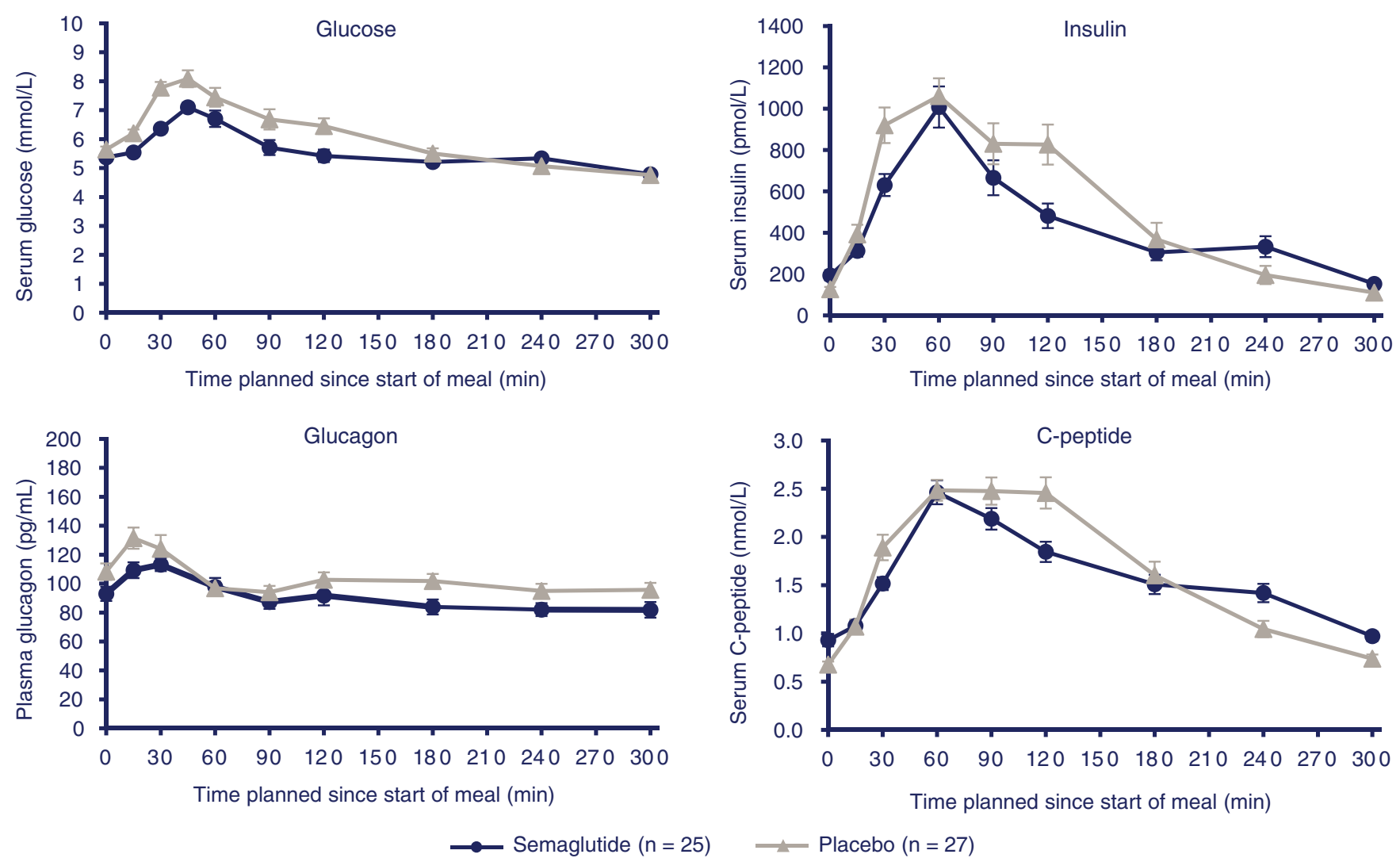

FIGURE 1 Mean glucose metabolism profiles after standardized, carbohydrate-rich breakfast. Error bars represent standard error

difference in postprandial increments $\left(\mathrm{iAUC}_{0-5 \mathrm{~h}}\right.$ ) for glucagon between semaglutide and placebo (Figure 1, Table 1).

Before and following the standardized fat-rich breakfast, fasting and postprandial values ( $\mathrm{iAUC}_{0-8 \mathrm{~h}}$ ) for glucagon tended to be lower with semaglutide than with placebo ( $-13 \%$ and $-27.3 \%$, respectively) (Figure S1, Table 1).

\section{3 | Lipid metabolism}

Fasting total cholesterol and HDL cholesterol were lower with semaglutide compared with placebo (ETR: 0.89 [95\% Cl: 0.86, 0.92]; $P<.0001$; and ETR: 0.92 [95\% Cl: 0.88, 0.96]; $P=.0002$, respectively), whereas no difference was observed for fasting LDL cholesterol (ETR: 0.95 [95\% Cl: 0.86, 1.06]; $P=.3906$ ). Fasting concentrations of TG and VLDL were significantly lower (12\% and $21 \%$, respectively) with semaglutide compared with placebo $(P<.02)$ (Table 2). No difference in FFA and ApoB-48 was observed.

Following the fat-rich breakfast, postprandial values (iAUC $\mathrm{C}_{0-8 \mathrm{~h}}$ ) were significantly lower for TG (-40.7\%), VLDL (-42.8\%) and ApoB$48(-49.6 \%)$ with semaglutide compared with placebo (ETD: $-4.51 \mathrm{mmol} h / \mathrm{L},-1.17 \mathrm{mmol} \mathrm{h} / \mathrm{L}$ and $-0.046 \mathrm{~g} \mathrm{~h} / \mathrm{L}$, respectively; $P<.01$ for all) (Figure 2; Table 2). No difference in FFA was observed.

\section{4 | Gastric emptying}

As assessed by paracetamol concentrations, gastric emptying during the first hour, following the standardized carbohydrate-rich breakfast, was $27 \%$ lower with semaglutide, compared with placebo $\left(A \cup C_{0-1 h}\right.$ ETR: 0.73 [95\% Cl: 0.61, 0.87]; $P=.0012$ ). There was no significant difference between treatments for the overall postprandial gastric emptying (AUC ${ }_{0-5 h}$ ETR: 0.94 [95\% Cl: 0.88; 1.01]) (Figure 3A).

\section{5 | Effect of gastric emptying on glucose response}

Following the standardized carbohydrate-rich breakfast, the postprandial increment for glucose within the first hour ( $\mathrm{iAUC}_{0-1 \mathrm{~h}}$ ) was $37.8 \%$ lower with semaglutide than with placebo (ETD: $-0.56 \mathrm{mmol} \mathrm{h} / \mathrm{L}$ [95\% Cl: $-0.88,-0.23$ ]; $P=.0018)$. When gastric emptying during the first hour after the meal was included as a covariate, treatment difference was less pronounced (ETD: $-0.33 \mathrm{mmol} h / \mathrm{L}$ [95\% Cl: $-0.70,0.05] ; P=.0829$ ), indicating that approximately $40 \%$ of the early glucose response may be explained by the rate of gastric emptying.

\section{6 | PYY response}

At the end of the 12-week treatment period, subjects receiving semaglutide $1.0 \mathrm{mg}$ had lower mean fasting PYY concentrations, compared with those receiving placebo (ETR: 0.72 [95\% Cl: 0.53; 0.98]; $P=.0397$ ). Postprandial values ( $\mathrm{AUUC}_{0-5 \mathrm{~h}}$ ) for PYY concentrations, following the standardized carbohydrate-rich breakfast, were $46.3 \%$ lower with semaglutide, compared with placebo (ETD: $-46.10 \mathrm{pg} \mathrm{h} / \mathrm{mL}$; $P=$.0097) (Figure 3B). 
TABLE 2 Lipid metabolism parameters after 12 weeks of treatment with semaglutide vs placebo

\begin{tabular}{|c|c|c|c|c|c|c|c|}
\hline \multirow[b]{2}{*}{$\begin{array}{l}\text { Lipid metabolism } \\
\text { parameters }\end{array}$} & \multicolumn{3}{|c|}{ Fasting values } & \multicolumn{4}{|c|}{ Postprandial values (iAUC ${ }_{0-8 \mathrm{~h}}$ ) following fat-rich breakfast } \\
\hline & ETR & $95 \% \mathrm{Cl}$ & $P$ & ETD & $95 \% \mathrm{Cl}$ & $P$ & $\begin{array}{l}\text { Relative } \\
\text { difference (\%) }\end{array}$ \\
\hline TGs & $0.88^{b}$ & $0.80,0.98$ & .0185 & $-4.51^{\mathrm{b}} \mathrm{mmol} \mathrm{h} / \mathrm{L}$ & $-6.15,-2.87$ & $<.0001$ & -40.7 \\
\hline VLDL & $0.79^{b}$ & $0.66,0.95$ & .0132 & $-1.17^{\mathrm{b}} \mathrm{mmol} \mathrm{h} / \mathrm{L}$ & $-2.03,-0.32$ & .0093 & -42.8 \\
\hline ApoB-48 & 1.02 & $0.86,1.21$ & .8376 & $-0.046^{\mathrm{b}} \mathrm{g} \mathrm{h} / \mathrm{L}$ & $-0.069,-0.022$ & .0003 & -49.6 \\
\hline FFA & 0.99 & $0.88,1.11$ & .8008 & $0.052 \mathrm{mmol} \mathrm{h} / \mathrm{L}$ & $-0.060,0.163$ & .3480 & 15.6 \\
\hline
\end{tabular}

Abbreviations: ApoB-48, apolipoprotein B48; Cl, confidence interval; ETD, estimated treatment difference (semaglutide - placebo); ETR, estimated treatment ratio (semaglutide/placebo); FFA, free fatty acids; iAUC ${ }_{0-8 \mathrm{~h}}$, incremental area under the 0 to 8-hour curve; TG, triglyceride; VLDL, very-low-density lipoprotein.

${ }^{a}$ Estimated treatment difference/estimated mean for placebo $\times 100 \%$.

${ }^{\mathrm{b}} P<.05$.
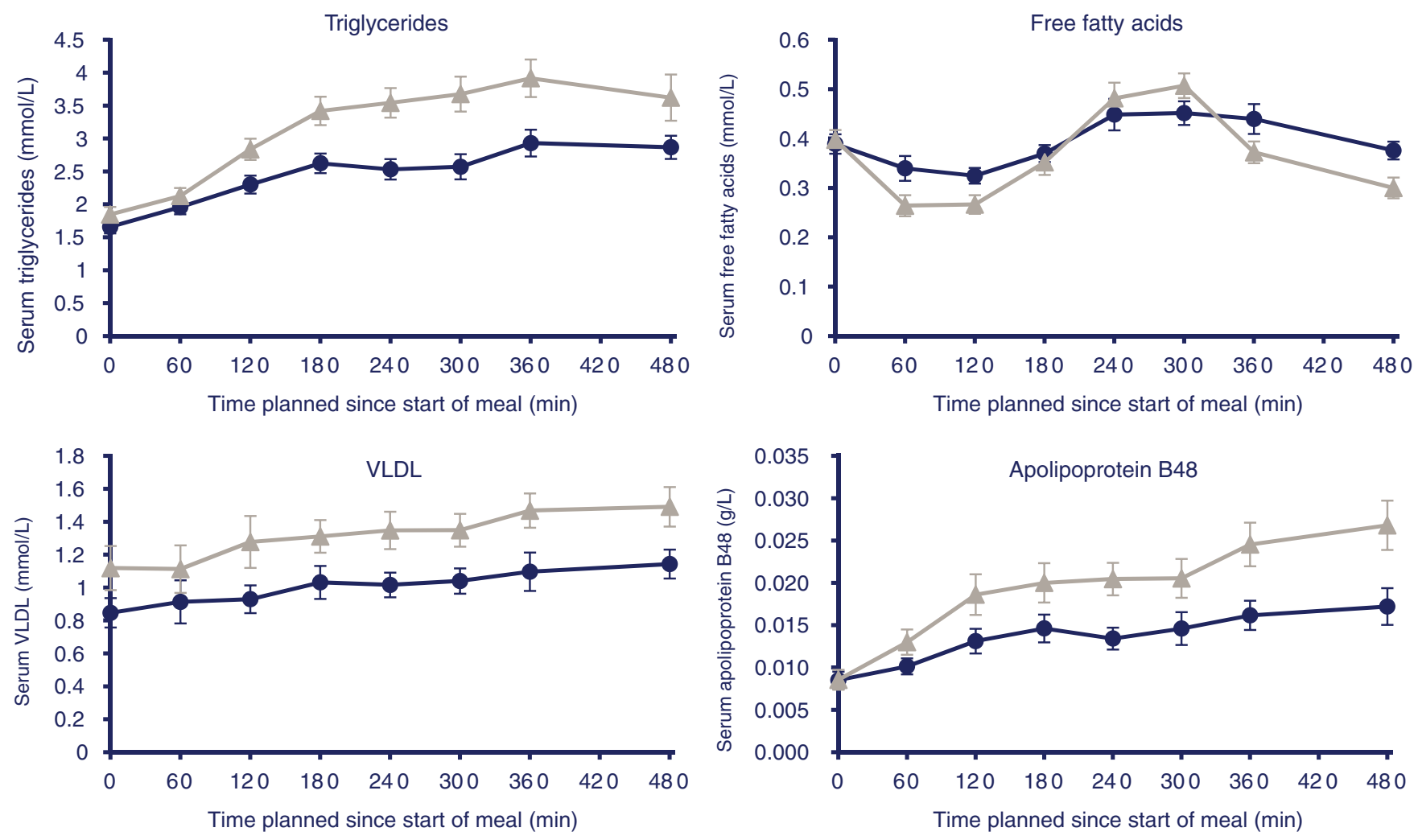

$\longrightarrow$ Semaglutide $(n=26)$

$\simeq$ Placebo $(n=28)$

FIGURE 2 Mean lipid metabolism profiles after standardized, fat-rich breakfast. Error bars represent standard error. Abbreviation: VLDL, verylow-density lipoprotein

\section{4 | DISCUSSION}

In this study we report that fasting and postprandial glucose and lipid metabolism were improved with semaglutide treatment compared with placebo.

Postprandial glucose and lipid metabolism are important aspects when considering overall glycaemic and lipid control because most individuals spend a significant amount of the day in a non-fasting state. ${ }^{19,31}$

Following 12 weeks of treatment with semaglutide, there were generally lower postprandial increments of glucose-related parameters, including glucose, glucagon, insulin and C-peptide. However, the differences in glucose parameters were less pronounced between treatments following the fat-rich breakfast, possibly as a result of the expected reduction in glucose absorption associated with a high fat intake, ${ }^{32}$ and/or the lower absolute amount of carbohydrate in the fatrich breakfast vs the carbohydrate-rich breakfast (50 g vs $83 \mathrm{~g}$ ). ${ }^{33}$

Our findings in a population with obesity, but not T2D, are in alignment with results from previous studies with GLP1RAs. ${ }^{15-17,34,35}$ Liraglutide has been shown to significantly reduce mean postprandial glucose and glucagon $\left(\mathrm{AUC}_{0-5 \mathrm{~h}}\right)$ compared with placebo, both in subjects with $\mathrm{T} 2 \mathrm{D},{ }^{15}$ and in obese, non-diabetic adults. ${ }^{35}$ Similarly, albiglutide and dulaglutide, both of which are once-weekly GLP-1RAs, have been shown to lower fasting and postprandial glucose concentrations. ${ }^{17,34}$ In relation to glycaemic control, GLP-1RAs increase insulin secretion in a glucose-dependent manner, 

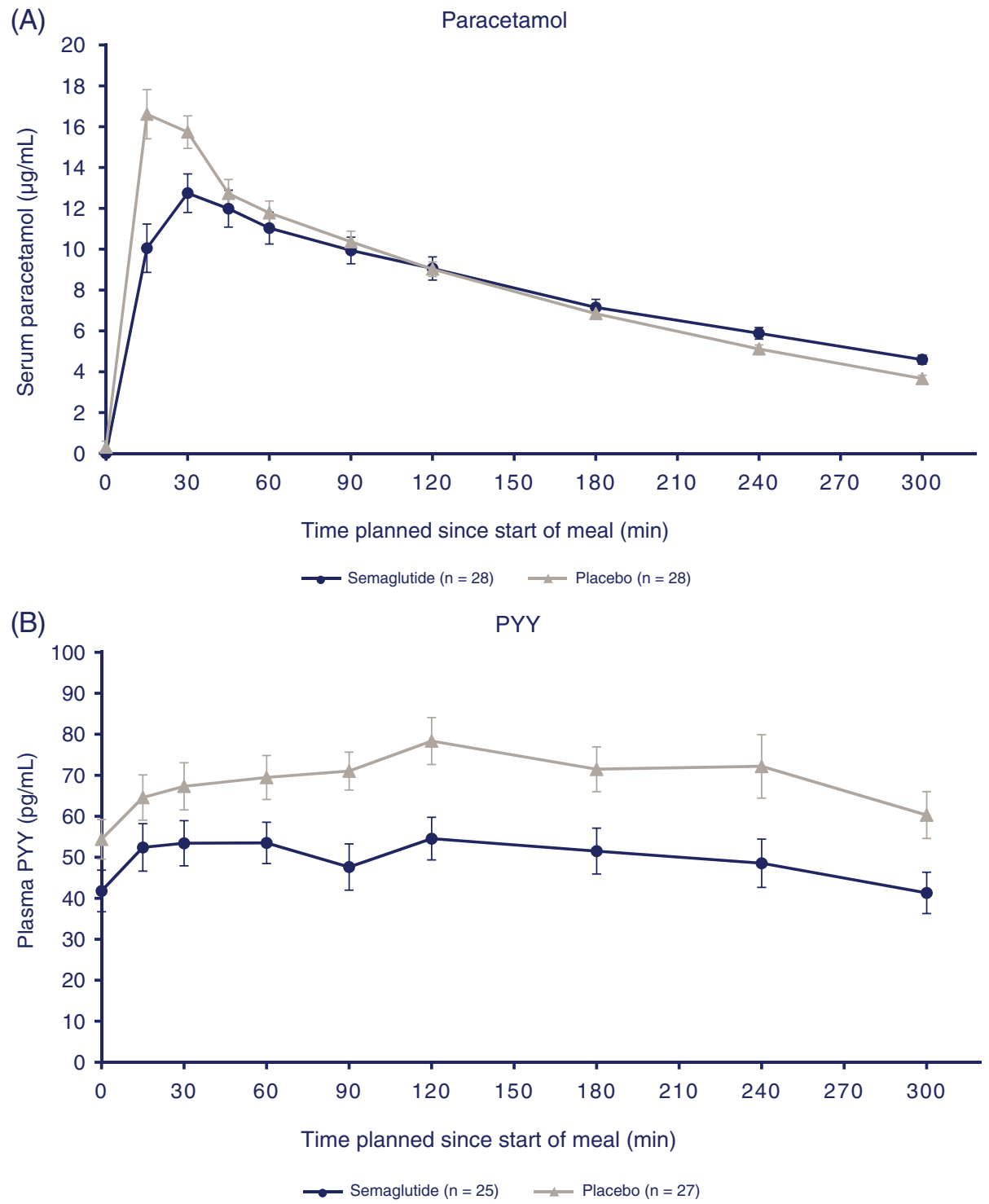

FIGURE 3 Gastric emptying: A, mean paracetamol profiles following standardized, carbohydrate-rich breakfast. B, Mean PYY profile following standardized, carbohydrate-rich breakfast. Error bars represent standard error. Abbreviation: PYY, peptide YY suppress glucagon and slow gastric emptying, which affects the postprandial glucose response. ${ }^{13,14,19}$ The observed reduction in postprandial insulin and C-peptide in this trial may be explained, in part, by the reduction in glucose concentrations observed after 12 weeks of treatment. It is conceivable that semaglutide may produce a greater response in subjects with T2D with higher glycaemia. ${ }^{15,35,36}$ In another 12-week study with semaglutide in subjects with T2D, a pronounced improvement of beta-cell function was shown, and the impact on 24-hour glucose, insulin and C-peptide responses during a test day with 3 standardized meals was similar to observations in the current study. ${ }^{36}$ The effects of semaglutide on insulin and glucose are interdependent. In the fasting state, the concentrations of insulin and C-peptide are significantly increased. However, after 12 weeks of treatment, in the postprandial state the lower insulin increments should be interpreted in light of the concurrent lower glucose increments.

Previously we reported an observed body weight reduction of $5.0 \mathrm{~kg}$ following 12 weeks of semaglutide treatment. ${ }^{27}$ Body weight loss is known to improve insulin sensitivity. ${ }^{37}$ Improved insulin sensitivity would result in a decrease in glucose concentrations and, thus, less insulin demand. Therefore, weight loss reported in this study may have affected the glucose and lipid responses. Similar findings have been reported with liraglutide, which improved both postprandial glycaemia and induced weight loss. ${ }^{35}$ The substantial reduction in body weight reported in this study may, therefore, be the effect of an indirect route by which semaglutide influences postprandial glycaemic and lipid parameters. The long-term effects of continuous subcutaneous infusion of GLP-1 also showed decreases in both fasting and postprandial glucose concentrations, as well as decreases in $\mathrm{HbA1c}$ and body weight. ${ }^{38}$

Our study is the first to investigate the effect of semaglutide treatment on postprandial lipid absorption and metabolism. Following a standardized fat-rich breakfast, subjects treated with semaglutide had lower postprandial TG, VLDL and ApoB-48 over 8 hours (iAUC $C_{0-8 \mathrm{~h}}$ ). Postprandial ApoB-48, a marker of TG uptake from the gut, is known to be involved in the assembly of chylomicron particles required for the absorption of TGs. ${ }^{39}$ Chylomicron production has been shown to be increased in subjects with T2D and insulin resistance. $^{39}$ In this study the lower postprandial TG concentrations corresponded well with lower postprandial ApoB-48 concentration profiles for semaglutide vs placebo. It is plausible that, by reducing the serum concentration of ApoB-48, semaglutide in turn reduces the 
postprandial absorption of serum TGs. In a series of studies in hamsters and mice, Hsieh and colleagues showed that the GLP-1 receptor is essential for regulation of the intestinal lipid and lipoprotein metabolism, through control of intestinal lipoprotein synthesis and secretion. ${ }^{40}$ This was confirmed in humans by Vergès and colleagues, who recently reported on the effects of liraglutide on the metabolism of ApoB-48. ${ }^{41}$ Treatment with liraglutide significantly decreased postprandial hyperlipidaemia in subjects with $T 2 D$ via a mechanism of reduced ApoB-48 production and increased ApoB-48 catabolism. ${ }^{41}$

The frequency of obesity is reported to be greater in consumers of high-fat diets than in consumers of low-fat diets. ${ }^{42}$ Therefore, the demonstrable effect of semaglutide on blood lipids during a high-fat meal is highly relevant for subjects with obesity, who often consume energy-dense, high-fat foods that contribute to hyperlipidaemia.

In our study, fasting concentrations of TG and VLDL were also significantly lower with semaglutide than with placebo. In addition, total cholesterol and HDL cholesterol were lower with semaglutide than with placebo, whereas LDL cholesterol appeared to be comparable between treatments. In longer-term studies with semaglutide, 1 to 2 years of treatment modestly improved various lipid parameters in subjects with T2D compared with placebo or treatment with sitagliptin. ${ }^{43,44}$ These findings are consistent with those for other GLP1RAs, including liraglutide and exenatide. ${ }^{18,45,46}$

Hyperlipidaemia is a well-known risk factor for cardiovascular diseases. ${ }^{47,48}$ Thus, lowering serum TGs may reduce the risk of cardiovascular diseases such as atherosclerosis. ${ }^{5}$ In particular, lowering of non-fasting TG could be of clinical importance as higher concentrations have been shown to be associated with an increased risk of myocardial infarction, ischaemic heart disease and death. ${ }^{48}$ The effect of semaglutide on cardiovascular outcomes in subjects with T2D has been reported in the 2-year SUSTAIN 6 study. ${ }^{44}$ Results from this study showed that, among subjects with T2D at high cardiovascular risk, the rate of first occurrence of death from cardiovascular causes, nonfatal myocardial infarction or nonfatal stroke was significantly lower in those receiving semaglutide than in those receiving placebo. ${ }^{44}$ The effect of semaglutide on postprandial glucose and lipid metabolism may have contributed to these findings.

GLP-1RAs have the capacity to slow gastric emptying in a variable but marked manner, when administered acutely, which may represent a key mechanism contributing to their glucose-lowering effect. ${ }^{19}$ However, some investigations indicate that this phenomenon is transient and the effect on gastric emptying diminishes over time $^{49,50}$ The differing durations of action of GLP-1RAs seem to influence gastric emptying with continued dosing. The slowing of gastric emptying induced by several long-acting GLP-1 agonists ${ }^{49,51}$ (although not by exenatide twice daily or lixisenatide) lessens with time, perhaps indicative of adaptation over time. ${ }^{19}$ In our study, after 12 weeks of treatment, there was no statistically significant difference between semaglutide and placebo for the overall rate of postprandial gastric emptying. A delayed gastric emptying response was detected during the first hour after the standardized breakfast compared with placebo. This finding is consistent with previous findings for liraglutide. ${ }^{18,19}$ Gastric emptying during the first hour was a significant covariate in the statistical analysis of postprandial glucose response following the standardized breakfast, indicating that approximately $40 \%$ of the initial glucose response could be explained by the rate of gastric emptying, and that gastric emptying contributed to the lower postprandial increase in glucose response observed when subjects were treated with semaglutide.

We used the paracetamol absorption test to measure the rate of gastric emptying. Although it provides an indirect estimation of gastric emptying, this technique is reported to correlate generally well with scintigraphy. ${ }^{52} \mathrm{~A}$ limitation with all gastric emptying tests is the considerable inter-individual variation; ${ }^{52}$ however, this was counteracted by intra-subject comparisons in this study. Despite claimed limitations in drawing conclusions about solids from paracetamol studies, ${ }^{52}$ it should be noted that paracetamol in this study was added to the semi-solid part of the meal (yoghurt). In a previous study investigating the effect of liraglutide on gastric emptying, ${ }^{18}$ a comparable set-up was used and similar results were observed with the paracetamol test and the octanoate breath test (labelling the solid part of the meal) during the same meal. Furthermore, the results on gastric emptying obtained in the current study agree with observations in other long-acting GLP-1RA studies. ${ }^{53,54}$

The lower PYY response observed with semaglutide is in alignment with a previous study in which GLP-1 infusions appeared to have an inhibitory effect on PYY release, suggesting possible feedback (suppression) of GLP-1 on L-cell function in the acute setting. ${ }^{55}$ GLP-1RAs have also been reported to reduce postprandial endogenous GLP-1 and PYY concentrations. ${ }^{56}$ As with GLP-1, PYY responses correlate with nutrient exposure in the gut. For the standardized breakfast, the amount consumed was the same for those receiving semaglutide and those receiving placebo, but a lower postprandial PYY response was expected with semaglutide treatment, because of the lower initial gastric emptying. The lower fasting level of PYY may further be explained by a semaglutide-induced lower food intake during the treatment period, reported from the same study. ${ }^{27}$ Therefore, it is not clear if the reduced PYY response in this study is the result of the semaglutide-induced direct suppression of L-cell secretion, or is an indirect result of lower postprandial stimulation of L-cells caused by delayed gastric emptying or by longer-term lower food intake because of the documented impact of semaglutide on appetite regulation. ${ }^{27}$

The strengths of this study include the crossover design, with subjects serving as their own control, the high degree of standardization, and the frequency of sampling, up to 5 and 8 hours after the standardized meals. A potential weakness is that, of those subjects receiving semaglutide, 4 did not ingest all of the standardized breakfast meal (consuming approximately 60\%-83\%) and, likewise, 2 subjects consumed only part of the standardized fat-rich breakfast. Therefore, related data derived from these subjects were excluded from the glucose and TG results. Nevertheless, sensitivity analyses confirmed the results from the primary analyses.

To conclude, fasting and postprandial glucose and lipid metabolism were improved after 12 weeks of treatment with semaglutide compared with placebo. Overall, 5 hours postprandial gastric emptying was similar for semaglutide and placebo; with semaglutide, however, a delay was observed during the first hour after a meal, possibly contributing to a slower entry of glucose into the circulation. 


\section{ACKNOWLEDGMENTS}

We thank all the participants, investigators and trial-site staff who were involved in the conduct of the trial. We also thank Haydn Liang, $\mathrm{PhD}$, and lan Seymour, $\mathrm{PhD}$, both from AXON Communications, for medical writing and editorial assistance.

\section{Conflict of interests}

M. B. A., A. F., J. B. H. and T. K. are full-time employees of, and hold shares in, Novo Nordisk A/S. A. B. has received research grants from Novo Nordisk. J. B. has received research, travel and accommodation grants within the submitted work from Novo Nordisk $A / S$, and advisory and speaker fees outside the submitted work from Novo Nordisk A/S.

\section{Author contributions}

J. B., A. F and J. B. H. designed the study. A. B. and J. B. conducted the study. T. K. participated in the data analysis. M. B. A., A. B., J. B., A. F. and J. B. H. participated in the collection, analysis and interpretation of data. All authors were involved in the writing and revision, and gave final approval, of the manuscript.

\section{ORCID}

Julie B. Hjerpsted (DD http://orcid.org/0000-0002-6938-786X John Blundell (iD http://orcid.org/0000-0002-7085-9596

\section{REFERENCES}

1. International Diabetes Federation. IDF Diabetes Atlas. 7th ed. IDF Web site. www.diabetesatlas.org/component/attachments/?task= download\&id=116. IDF, 2015. Accessed August 16, 2017.

2. American Diabetes Association. Classification and diagnosis of diabetes. Diabetes Care. 2016;39:S13-S22.

3. Raccah D, Chou E, Colagiuri S, et al. A global study of the unmet need for glycemic control and predictor factors among patients with type 2 diabetes mellitus who have achieved optimal fasting plasma glucose control on basal insulin. Diabetes Metab Res Rev. 2017;33: https://doi. org/10.1002/dmrr.2858. [Epub 13 Oct 2016].

4. American Diabetes Association. Cardiovascular disease and risk management. Diabetes Care. 2017;40:S75-S87.

5. Stone NJ, Robinson JG, Lichtenstein AH, et al; American College of Cardiology/American Heart Association Task Force on Practice Guidelines. 2013 ACC/AHA guideline on the treatment of blood cholesterol to reduce atherosclerotic cardiovascular risk in adults: a report of the American College of Cardiology/American Heart Association Task Force on Practice Guidelines. Circulation. 2014;129: S1-S45.

6. Ronveaux CC, Tome D, Raybould HE. Glucagon-like peptide 1 interacts with ghrelin and leptin to regulate glucose metabolism and food intake through vagal afferent neuron signaling. J Nutr. 2015;145:672-680.

7. Habib AM, Richards P, Rogers GJ, Reimann F, Gribble FM. Colocalisation and secretion of glucagon-like peptide 1 and peptide $Y Y$ from primary cultured human $\mathrm{L}$ cells. Diabetologia. 2013;56:1413-1416.

8. Meier JJ, Gethmann A, Götze O, et al. Glucagon-like peptide 1 abolishes the postprandial rise in triglyceride concentrations and lowers levels of non-esterified fatty acids in humans. Diabetologia. 2006;49:452-458.

9. Flint A, Raben A, Astrup A, Holst JJ. Glucagon-like peptide 1 promotes satiety and suppresses energy intake in humans. J Clin Invest. 1998;101:515-520.
10. Flint A, Raben A, Ersbøll AK, Holst JJ, Astrup A. The effect of physiological levels of glucagon-like peptide-1 on appetite, gastric emptying, energy and substrate metabolism in obesity. Int J Obes Relat Metab Disord. 2001;25:781-792.

11. Wettergren A, Schjoldager B, Mortensen PE, Myhre J, Christiansen J, Holst JJ. Truncated GLP-1 (proglucagon 78-107-amide) inhibits gastric and pancreatic functions in man. Dig Dis Sci. 1993;38:665-673.

12. Pi-Sunyer X, Astrup A, Fujioka K, et al; SCALE Obesity and Prediabetes NN8022-1839 Study Group. A randomized, controlled trial of $3.0 \mathrm{mg}$ of liraglutide in weight management. $N$ Engl J Med. 2015;373:11-22.

13. Hare KJ, Vilsbøll T, Asmar M, Deacon CF, Knop FK, Holst JJ. The glucagonostatic and insulinotropic effects of glucagon-like peptide 1 contribute equally to its glucose-lowering action. Diabetes. 2010;59:1765-1770.

14. Kondo Y, Satoh S, Osada UN, Terauchi Y. Early liraglutide treatment improves beta-cell function in patients with type 2 diabetes: a retrospective cohort study. Endocr J. 2015;62:971-980.

15. Flint A, Kapitza C, Hindsberger C, Zdravkovic M. The once-daily human glucagon-like peptide-1 (GLP-1) analog liraglutide improves postprandial glucose levels in type 2 diabetes patients. Adv Ther. 2011;28:213-226.

16. Linnebjerg $\mathrm{H}$, Kothare PA, Skrivanek $Z$, et al. Exenatide: effect of injection time on postprandial glucose in patients with type 2 diabetes. Diabet Med. 2006;23:240-245.

17. Matthews JE, Stewart MW, De Boever EH, et al; Albiglutide Study Group. Pharmacodynamics, pharmacokinetics, safety, and tolerability of albiglutide, a long-acting glucagon-like peptide-1 mimetic, in patients with type 2 diabetes. J Clin Endocrinol Metab. 2008;93:4810-4817.

18. Hermansen $K$, Baekdal TA, Düring $M$, et al. Liraglutide suppresses postprandial triglyceride and apolipoprotein B48 elevations after a fat-rich meal in patients with type 2 diabetes: a randomized, doubleblind, placebo-controlled, cross-over trial. Diabetes Obes Metab. 2013;15:1040-1048.

19. Marathe CS, Rayner CK, Jones KL, Horowitz M. Relationships between gastric emptying, postprandial glycemia, and incretin hormones. Diabetes Care. 2013;36:1396-1405.

20. Uccellatore A, Genovese S, Dicembrini I, Mannucci E, Ceriello A Comparison review of short-acting and long-acting glucagon-like peptide-1 receptor agonists. Diabetes Ther. 2015;6:239-256.

21. Lau J, Bloch P, Schäffer L, et al. Discovery of the once-weekly glucagon-like peptide-1 (GLP-1) analogue semaglutide. J Med Chem. 2015;58:7370-7380.

22. Saini SD, Schoenfeld P, Kaulback K, Dubinsky MC. Effect of medication dosing frequency on adherence in chronic diseases. Am J Manag Care. 2009;15:e22-e33.

23. Kapitza C, Nosek L, Jensen L, Hartvig H, Jensen CB, Flint A. Semaglutide, a once-weekly human GLP-1 analog, does not reduce the bioavailability of the combined oral contraceptive, ethinylestradiol/ levonorgestrel. J Clin Pharmacol. 2015;55:497-504.

24. Marbury TC, Flint A, Jacobsen JB, Derving Karsbol J, Lasseter K. Pharmacokinetics and tolerability of a single dose of semaglutide, a human glucagon-like peptide- 1 analog, in subjects with and without renal impairment. Clin Pharmacokinet. 2017;56:1381-1390.

25. Madsbad S, Kielgast U, Asmar M, Deacon CF, Torekov SS, Holst JJ. An overview of once-weekly glucagon-like peptide-1 receptor agonists-available efficacy and safety data and perspectives for the future. Diabetes Obes Metab. 2011;13:394-407.

26. Nauck MA, Petrie JR, Sesti G, et al; Study 1821 Investigators. A phase 2 , randomized, dose-finding study of the novel once-weekly human GLP-1 analog, semaglutide, compared with placebo and open-label liraglutide in patients with type 2 diabetes. Diabetes Care 2016;39:231-241.

27. Blundell J, Finlayson G, Axelsen MB, et al. Effects of once-weekly semaglutide on appetite, energy intake, control of eating, food preference and body weight in subjects with obesity. Diabetes Obes Metab. 2017;19:1242-1251.

28. European Agency for the Evaluation of Medicinal Products. International Conference on Harmonisation-World Health Organization. Guideline for Good Clinical Practice [EMEA Web site]. ICH 
Harmonised Tripartite Guideline. Good Clinical Practice, 2017. http:// www.ema.europa.eu/docs/en_GB/document_library/Scientific guideline/2009/09/WC500002874.pdf. Accessed August 16, 2017.

29. World Medical Association. Declaration of Helsinki. Ethical Principles for Medical Research Involving Human Subjects. 52nd WMA General Assembly, Edinburgh, Scotland, October 2000. Last amended with Note of Clarification on Paragraph 29 by the WMA General Assembly, Washington 2002; and Note of Clarification on Paragraph 30 by the WMA General assembly, Tokyo, 2004. http://www.wma.net/en/ 30publications/10policies/b3/ Accessed August 16, 2017.

30. Medhus AW, Lofthus CM, Bredesen J, Husebye E. Gastric emptying: the validity of the paracetamol absorption test adjusted for individual pharmacokinetics. Neurogastroenterol Motil. 2001;13: 179-185.

31. Lopez-Miranda J, Marin C. Dietary, physiological, and genetic impacts on postprandial lipid metabolism. In: Montmayeur JP, le Coutre J, eds. Fat Detection: Taste, Texture, and Post Ingestive Effects. Boca Raton, FL: CRC Press; 2009.

32. Pi-Sunyer FX. Glycemic index and disease. Am J Clin Nutr. 2002;76:290S-S298.

33. Pearce KL, Noakes M, Keogh J, Clifton PM. Effect of carbohydrate distribution on postprandial glucose peaks with the use of continuous glucose monitoring in type 2 diabetes. Am J Clin Nutr. 2008;87: 638-644.

34. Umpierrez GE, Blevins T, Rosenstock J, et al; EGO Study Group. The effects of LY2189265, a long-acting glucagon-like peptide-1 analogue, in a randomized, placebo-controlled, double-blind study of overweight/obese patients with type 2 diabetes: the EGO study. Diabetes Obes Metab. 2011;13:418-425.

35. van Can J, Sloth B, Jensen CB, Flint A, Blaak EE, Saris WH. Effects of the once-daily GLP-1 analog liraglutide on gastric emptying, glycemic parameters, appetite and energy metabolism in obese, non-diabetic adults. Int J Obes (Lond). 2014;38:784-793.

36. Kapitza C, Dahl K, Jacobsen JB, Axelsen MB, Flint A. Effects of semaglutide on beta cell function and glycaemic control in participants with type 2 diabetes: a randomised, double-blind, placebo-controlled trial. Diabetologia. 2017;60:1390-1399.

37. Schenk S, Harber MP, Shrivastava CR, Burant CF, Horowitz JF. Improved insulin sensitivity after weight loss and exercise training is mediated by a reduction in plasma fatty acid mobilization, not enhanced oxidative capacity. J Physiol. 2009;587:4949-4961.

38. Zander M, Madsbad S, Madsen JL, Holst JJ. Effect of 6-week course of glucagon-like peptide 1 on glycaemic control, insulin sensitivity, and beta-cell function in type 2 diabetes: a parallel-group study. Lancet. 2002;359:824-830.

39. Hussain MM. Intestinal lipid absorption and lipoprotein formation. Curr Opin Lipidol. 2014;25:200-206.

40. Hsieh J, Longuet C, Baker CL, et al. The glucagon-like peptide 1 receptor is essential for postprandial lipoprotein synthesis and secretion in hamsters and mice. Diabetologia. 2010;53:552-561.

41. Vergès $B$, Duvillard $L$, Bouillet $B$, et al. Liraglutide reduces postprandial hyperlipidaemia by increasing apoB48 catabolism and by reducing apoB48 production. Geneva, Switzerland: 52nd EASD Annual Meeting 2016; Abstract \#635.

42. Blundell JE, Lawton CL, Cotton JR, Macdiarmid JI. Control of human appetite: implications for the intake of dietary fat. Annu Rev Nutr. 1996;16:285-319.

43. Ahrén B, Masmiquel L, Kumar H, et al. Efficacy and safety of onceweekly semaglutide versus once-daily sitagliptin as an add-on to metformin, thiazolidinediones, or both, in patients with type 2 diabetes
(SUSTAIN 2): a 56-week, double-blind, phase 3a, randomised trial. Lancet Diabetes Endocrinol. 2017;5:341-354.

44. Marso SP, Bain SC, Consoli A, et al; SUSTAIN-6 Investigators. Semaglutide and cardiovascular outcomes in patients with type 2 diabetes. N Engl J Med. 2016;375:1834-1844.

45. Voukali M, Kastrinelli I, Stragalinou S, et al. Study of postprandial lipaemia in type 2 diabetes mellitus: exenatide versus liraglutide. J Diabetes Res. 2014;2014:304032.

46. Ariel D, Kim SH, Abbasi F, Lamendola CA, Liu A, Reaven GM. Effect of liraglutide administration and a calorie-restricted diet on lipoprotein profile in overweight/obese persons with prediabetes. Nutr Metab Cardiovasc Dis. 2014;24:1317-1322.

47. Langsted A, Freiberg JJ, Tybjaerg-Hansen A, Schnohr P, Jensen GB, Nordestgaard BG. Nonfasting cholesterol and triglycerides and association with risk of myocardial infarction and total mortality: the Copenhagen City Heart Study with 31 years of follow-up. J Intern Med. 2011;270:65-75.

48. Nordestgaard BG, Langsted A, Freiberg JJ. Nonfasting hyperlipidemia and cardiovascular disease. Curr Drug Targets. 2009;10:328-335.

49. Jelsing J, Vrang N, Hansen G, Raun K, Tang-Christensen M, Knudsen LB. Liraglutide: short-lived effect on gastric emptying - long lasting effects on body weight. Diabetes Obes Metab. 2012;14:531-538.

50. Nauck MA, Kemmeries G, Holst JJ, Meier JJ. Rapid tachyphylaxis of the glucagon-like peptide 1-induced deceleration of gastric emptying in humans. Diabetes. 2011;60:1561-1565.

51. Drucker DJ, Buse JB, Taylor K, et al; DURATION-1 Study Group. Exenatide once weekly versus twice daily for the treatment of type 2 diabetes: a randomised, open-label, non-inferiority study. Lancet. 2008;372:1240-1250.

52. Willems M, Quartero AO, Numans ME. How useful is paracetamol absorption as a marker of gastric emptying? A systematic literature study. Dig Dis Sci. 2001;46:2256-2262.

53. Trulicity (Dulaglutide) Prescribing Information. Indianapolis, IN: Eli Lilly and Company, 2014. http://pi.lilly.com/us/trulicity-uspi.pdf Accessed August 16, 2017.

54. Tanzeuim (Albiglutide) Prescribing Information. Willington, DE: GlaxoSmithKline LLC, 2014. https://www.accessdata.fda.gov/ drugsatfda_docs/label/2014/125431s000lbl.pdf Accessed August 16, 2017.

55. Naslund E, Bogefors J, Skogar S, et al. GLP-1 slows solid gastric emptying and inhibits insulin, glucagon, and PYY release in humans. Am J Physiol. 1999;277:R910-R916.

56. Lin J, Hodge RJ, O'Connor-Semmes RL, Nunez DJ. GSK2374697, a long duration glucagon-like peptide-1 (GLP-1) receptor agonist, reduces postprandial circulating endogenous total GLP-1 and peptide YY in healthy subjects. Diabetes Obes Metab. 2015;17:1007-1010.

\section{SUPPORTING INFORMATION}

Additional Supporting Information may be found online in the supporting information tab for this article.

How to cite this article: Hjerpsted JB, Flint A, Brooks A, Axelsen MB, Kvist T, Blundell J. Semaglutide improves postprandial glucose and lipid metabolism, and delays first-hour gastric emptying in subjects with obesity. Diabetes Obes Metab. 2018;20:610-619. https://doi.org/10.1111/dom. 13120 